\title{
The Impact of Chronic Obstructive Pulmonary Disease on Long-term Disability Costs
}

\author{
DAVID TINKELMAN, MD; ROBERT J. NORDYKE, PhD; SHARON ISONAKA, MD; \\ DOROTHY GEORGE, PharmD; KEITH DESFOSSES, MBA; and DMITRY NONIKOV, MD
}

\begin{abstract}
OBJECTIVES: Chronic obstructive pulmonary disease (COPD) as a cause of disability with subsequent costs remains poorly recognized. The small, growing body of literature on COPD shows that it is one of the leading causes of missed work-greater than asthma or diabetes. However, much less is known about the impact of COPD on long-term disability (LTD). Because the health care burden for disabled, working-age patients will fall heavily on managed care organizations, better estimates of the economic and pharmacoeconomic costs of COPD are required. We seek to improve understanding of the burden of COPD on several national LTD programs.
\end{abstract}

METHODS: We reviewed occupational health and disability literature and government statistics to determine how long-term, respiratory-related disability is addressed by disability pension programs in 8 developed countries (Canada, France, Germany, Italy, Japan, Spain, the United Kingdom, and the United States). We then applied respiratory-specific disability definitions to country-specific population and pension information to estimate the potential burden of COPD on LTD insurance programs in each country.

RESULTS: Comprehensive, relevant data to evaluate respiratory-related disability are lacking. Of the study countries, only the United States has explicit respiratoryspecific criteria for disability eligibility, which are based solely on spirometry. We estimate that the total burden of COPD in the study countries may range from $\$ 5$ billion to as high as $\$ 25$ billion per year if all persons who met U.S. eligibility criteria for respiratory-related disability were granted compensation.

CONCLUSION: The potential burden of COPD on LTD programs may be large. The lack of standard criteria for respiratory-related disability may lead to underrecognition of COPD's true potential impact. Further work is needed to develop consistent and cost-effective ways to measure the impact of COPD and to assist in disability determination for COPD patients.

KEYWORDS: Chronic obstructive pulmonary disease, Disability insurance, Costs and cost analysis

J Manag Care Pharm. 2005:11(1):25-32
Authors

DAVID TINKELMAN, MD, is vice president, health initiatives, National Jewish Medical and Research Center, Denver, Colorado. ROBERT J. NORDYKE, PhD, is associate director, SHARON ISONAKA, MD, is principal investigator, and DOROTHY GEORGE, PharmD, is associate director, Cerner Health Insights (formerly Zynx Health), Beverly Hills, California; Nordyke is also an adjunct assistant professor, UCLA School of Public Health, Los Angeles, California. KEITH DESFOSSES, MBA, is a senior consultant, Constella Health Strategies, Cambridge, Massachusetts. DMITRY NONIKOV, MD, is a consultant in Wiesbaden, Germany.

AUTHOR CORRESPONDENCE AND ARTICLE REPRINTS: David Tinkelman, MD, National Jewish Medical and Research Center, 1400 Jackson St., BB M306, Denver, CO 80206. Tel: (303) 398-1519; Fax: (303) 270-2220;

E-mail: tinkelmand@NJC.org

Copyright $@ 2005$, Academy of Managed Care Pharmacy. All rights reserved. hronic obstructive pulmonary disease (COPD) is a prevalent disease whose management incurs very high expenditures and exacts significant economic losses worldwide. In the United States, the age-adjusted prevalence of COPD is estimated at 60 per 1,000 persons above the age of 25 years. ${ }^{1}$ Internationally, reports of prevalence rates vary from $4 \%$ to $11 \%$. $^{2}$ Worldwide, the burden of COPD in disabilityadjusted life years was estimated to be twelfth highest (29.1) in 1990 and is projected to rise to fifth place by 2020. ${ }^{3}$ Prevalence of the disease increases with age, and it is associated with certain risk factors of which the most important is smoking. Passive smoking, exposure to occupational dust and chemicals, infections, and genetic predisposition are other less strongly associated factors. ${ }^{1}$

COPD places a substantial burden on patients by causing decreased lung function and associated symptoms. ${ }^{4-6}$ Individuals with COPD have significantly poorer functional health than the average adult. ${ }^{7}$ In addition, acute exacerbations of COPD lead to further erosion of quality of life, absenteeism, and greater use of health care resources. ${ }^{4,5}$ COPD is preventable but not fully reversible (GOLD definition ${ }^{8}$ ). The slow, inexorable decline in health toward the terminal phase plays a role in creating a prolonged period of need for compensation and appropriate health care. In the United States, the burden of providing care for disabled, working-age patients will fall heavily on managed care organizations; better estimates of the economic and pharmacoeconomic costs of COPD are required.

These costs will likely be substantial. In the United States, the total economic burden of COPD was estimated to be $\$ 32.1$ billion in 2002, with direct medical costs accounting for $\$ 18$ billion. Disability and premature death due to COPD cost the United States an additional \$14.1 billion in lost income. ${ }^{1}$ Disability payments to incapacitated workers by national governments alone are quite large, averaging nearly 1\% of national gross domestic product for the 8 countries reviewed in this report. ${ }^{9}$ Further, an economic analysis of data from a largescale international survey conducted in 7 countries (Canada, France, Italy, the Netherlands, Spain, the United Kingdom, and the United States) estimated the total economic burden of COPD to be $\$ 5,646$ annually per patient. ${ }^{10}$

Although the drivers of direct medical cost expenditures are increasingly recognized throughout the world, the impact of COPD on worker disability is less well understood. A recent study of California adults showed that COPD has a much greater impact than asthma on absence from work, perceived inability to work, and perceived limitation in type or amount of work. ${ }^{11}$ The prevalence of current employment among adults 


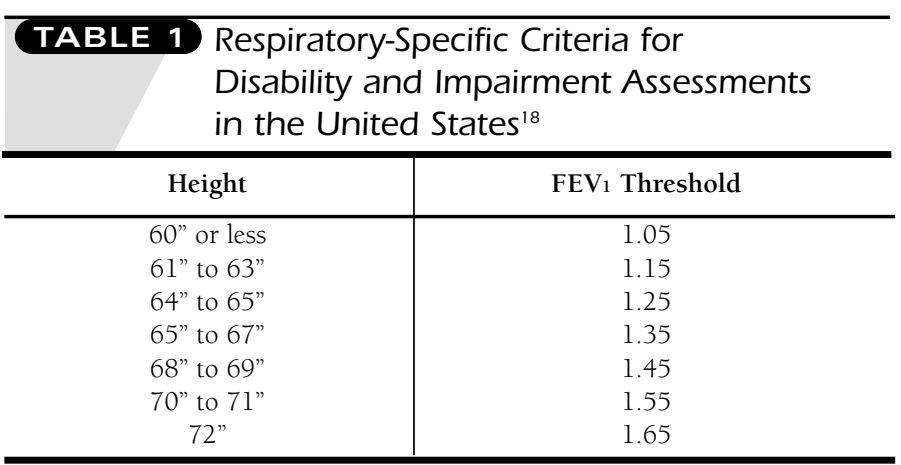

with COPD was 46.5\%, whereas current employment among those with asthma was $67.6 \%$. The risk for someone with COPD experiencing a prolonged absence from work was almost 3 times that of a normal population (OR 2.92). This is not the case for asthma or any other respiratory disease. Adults with COPD were also more likely to indicate a perceived inability to work $(\mathrm{OR}=12.90)$. Such individual-level outcomes translate into significant productivity losses at the national level. In the United States, COPD is the sixth leading cause of lost workdays after back problems, mood disorders, motor vehicle accidents, acute respiratory infections, and arthropathies. ${ }^{12}$

This paper estimates the impact of COPD on the national longterm disability (LTD) programs, the primary source of compensation for LTD, in 8 countries. There is no strict definition of LTD that can be applied uniformly to all 8 study countries ${ }^{13,14}$; nonetheless, LTD is generally defined as an inability to engage in full-time employment for 6 months or more due to a medical condition. Despite the large burden that COPD poses, ${ }^{2,15,16}$ the magnitude of LTD due to COPD still remains largely unrecognized. There is very little available literature to document how COPD impacts LTD insurance programs. Moreover, efforts to increase the recognition and diagnosis of $\mathrm{COPD}^{8}$ can be predicted to increase patient awareness, and the future impact of COPD on LTD may be even greater. For instance, Danish researchers found that over a 20-year period (1977-1996), the mean $\mathrm{FEV}_{1}$ (forced expiratory volume in 1 second) of COPD patients seeking a disability pension increased from $45 \%$ of predicted normal to $53 \%$ of predicted normal $(P<0.05),{ }^{17}$ suggesting that, over time, more and healthier people are seeking compensation.

To better understand the linkage between COPD and LTD insurance, this study seeks to answer the following:

- How is respiratory-related LTD assessed and defined in several developed countries?

- What is the potential financial impact of COPD on LTD pensions in these countries?

\section{Methods}

The analysis consisted of a 2-phase approach. First, we performed a review of the international occupational health and disability literature (available in the English language) to identify all articles that addressed respiratory-related disability, with a particular focus on COPD. This literature was supplemented with review and assessment of published government statistics for the 8 developed countries of interest for this analysis: Canada, France, Germany, Italy, Japan, Spain, the United Kingdom, and the United States. These countries were selected for inclusion because of the availability of English-language literature and the presence of large national pension programs.

Second, based upon the information from the above review, we calculated a standardized estimate of the financial burden of COPD due to LTD for each nation. These estimates were derived by multiplying (1) an estimate of the number of working-age persons with respiratory disability by (2) the LTD compensation rates for each country. Reflecting the very limited availability of data on this subject, this method was necessarily simplistic and subject to a number of assumptions as detailed below. The steps in the cost estimation were as follows:

1. We used the U.S. Social Security Administration (SSA) spirometry guidelines as a standard to estimate the number of persons eligible for respiratory-related disability. Our review of the English-language literature and government statistics indicated this was the only objective, respiratoryspecific criterion used in definition of disability due to respiratory impairment. ${ }^{18}$ An objective measure such as this was essential for estimation of the number of persons in our calculations. The SSA criteria for disability eligibility are listed in Table 1 .

2. We determined the proportion of the U.S. working-age population (20 - 64 years) that meets these spirometric criteria using the individual-level data on height and spirometry from the U.S. Third National Health and Nutrition Evaluation Survey (NHANES III). A complete description of the NHANES III survey methodology has been previously published. ${ }^{19}$ The age range of 20 through 64 years was chosen to be consistent with population data for other countries (which use age 20 as a lower cutoff point and the common retirement age of 65 as the upper cutoff point). Regarding that proportion as the maximum number of potentially eligible persons, we further searched government statistics to find the number of people who actually receive compensation. We regarded this as the minimum number of eligible persons.

3. The SSA spirometric criteria are only one component of the disability determination decision in the United States; not all persons falling below the $\mathrm{FEV}_{1}$ threshold for their height will be granted disability compensation. As such, we view these criteria as generating an upper bound on the estimated number of persons granted compensation. This upper bound was $0.54 \%$ of the population between the ages of 20 and 64 years, or 896,500 persons. The number of persons granted LTD compensation by the SSA in 2002-178,300represents the lower-bound estimate in our calculations. ${ }^{20}$ 


\begin{tabular}{|c|c|c|c|c|c|c|c|c|}
\hline & & & & & & D Preval & & \\
\hline Country & Study & $\begin{array}{l}\text { Diagnostic } \\
\text { Approach }\end{array}$ & $\begin{array}{c}\text { Nationally } \\
\text { Representative }\end{array}$ & Age (Years) & $\begin{array}{l}\text { Overall } \\
\text { Average }\end{array}$ & Males & Female & $\begin{array}{l}\text { \% Difference } \\
\text { From U.S. }\end{array}$ \\
\hline Canada & Chen $^{31}$ & Patient report & Yes & $35-44$ & 2.7 & 1.8 & 3.5 & -60 \\
\hline France & Rennard $^{32}$ & Patient report & Yes & $>45$ & 3.2 & & & -53 \\
\hline Germany & NA & NA & NA & NA & NA & & & 0 \\
\hline Italy & Viegi $^{33}$ & Spirometry only & Yes & $\geq 25$ & 11.0 & 12.5 & 11.8 & 62 \\
\hline Japan & Fukuchi $^{34}$ & Spirometry only & Yes & & 10.4 & & & 53 \\
\hline Spain & Peña ${ }^{35}$ & Spirometry only & Yes & $40-69$ & 9.1 & 14.3 & 3.9 & 34 \\
\hline $\begin{array}{l}\text { United } \\
\text { Kingdom }\end{array}$ & Dickinson $^{36}$ & $\begin{array}{l}F_{1}<\text { fifth centile } \\
+ \text { reversibility test }\end{array}$ & No & $60-75$ & 9.9 & & & 46 \\
\hline United States & Mannino $^{37}$ & Spirometry only & Yes & $\geq 17$ & 6.8 & & & 0 \\
\hline
\end{tabular}

The ratio between the lower- and upper-bound estimates is approximately 1 to 5 .

- The maximum and minimum estimates reflect different aspects of disability determination. The maximum is an estimate of all persons eligible for disability based upon SSA spirometric criteria alone. Thus, it is strongly associated with the prevalence and severity of COPD in a particular country. The lower-bound figure estimates the current number of persons granted disability as being the same as in the United States and thus reflects administrative procedures and the multifactor nature of physical disability.

4. Sensitivity analyses were performed on the estimated numbers of persons eligible for disability compensation using data on COPD prevalence in study countries. Halbert et al. ${ }^{2}$ recently summarized estimated prevalence of COPD in many countries. They found wide variation in methods, representativeness of study samples, and final prevalence estimates. We used prevalence estimates from studies with the most representative samples and objective measurement techniques available. Estimated numbers of disabled persons were adjusted in this analysis based on the measured prevalence of COPD in study countries relative to its prevalence in the United States. For example, if the prevalence in Country A was 50\% lower than the prevalence of COPD in the United States, the estimated number of disabled persons was reduced by $50 \%$. COPD prevalence estimates used are reported in Table 2.

5. Finally, we calculated maximum and minimum expected payments using the estimated eligible persons and the average benefit levels for each country. Total payments were also calculated for the estimates adjusted for COPD prevalence. We calculated total payments at a national level and respiratoryrelated disability payments per person of working age.

All results were presented in U.S. dollars (USD) by con- verting local currencies into USD using the exchange rate prevailing July 1 of the reference year; except where noted, the reference year is 2002 .

\section{Results}

\section{Disability Programs}

Benefits paid to those disabled by respiratory conditions are part of much larger social insurance programs administered by various government agencies. In many countries, employers bear a significant financial burden for national disability pension programs. Table 3 provides a synopsis of funding sources and benefit levels of national disability pensions in each of the study countries.

Disability pension program similarities across the 8 countries include the following:

- Governments often provide substantial support for the programs from general funds, with the exception of Spain. In the United States, a variable contribution is made from U.S. treasury general revenues toward income supplements. The primary burden is financed through social security payroll taxes paid by workers and their employers. The Japanese government makes the greatest contribution, with up to one third of program costs. The United Kingdom's treasury may subsidize the program by up to $17 \%$ of total benefits payments; this is in addition to costs of means testing (determining individual eligibility) for the program.

- Benefits vary according to one or more of the following: age, years of contributions, and average earnings for a fixed time period prior to disability. Average benefits range from 21\% (Japan) to $73 \%$ (United Kingdom) of average private-sector wages. This wide variation appears to depend on the social welfare ideology of the nation under consideration, as our results showed only a weak correlation with percentage 


\begin{tabular}{|c|c|c|c|c|c|}
\hline \multirow[b]{2}{*}{ Country } & \multicolumn{2}{|c|}{$\begin{array}{l}\text { Private Sector } \\
\text { Contributions }\end{array}$} & \multirow[b]{2}{*}{$\begin{array}{l}\text { Government } \\
\text { Funding }\end{array}$} & \multirow[b]{2}{*}{$\begin{array}{l}\text { Average } \\
\text { Benefit/ } \\
\text { Month } \\
\text { (U.S. \$) }\end{array}$} & \multirow[b]{2}{*}{$\begin{array}{c}\% \text { of } \\
\text { Average } \\
\text { Wage }\end{array}$} \\
\hline & $\begin{array}{l}\text { Workers } \\
\text { (\% of } \\
\text { Earnings) }\end{array}$ & \begin{tabular}{|c|} 
Employers \\
(\% of \\
Payroll)
\end{tabular} & & & \\
\hline Canada $^{21}$ & 3.5 & 3.5 & $\begin{array}{l}\text { Means testing } \\
\text { and cost of } \\
\text { basic pension }\end{array}$ & 532 & 24 \\
\hline France $^{14}$ & 6.55 & $8.2-9.8$ & Variable subsidies & 1,141 & 50 \\
\hline Germany $^{14}$ & 9.75 & 9.75 & $\begin{array}{l}\text { Subsidies for } \\
\text { shortfalls }\end{array}$ & 1,026 & 58 \\
\hline Italy $^{14}$ & $8.89-9.9$ & 23.81 & $\begin{array}{l}\text { Means testing } \\
\text { and subsidies } \\
\text { for shortfalls }\end{array}$ & 438 & 38 \\
\hline $\operatorname{Japan}^{22}$ & 8.675 & 8.675 & $\begin{array}{l}\text { Administrative } \\
\text { costs and up } \\
\text { to } 33 \% \text { of } \\
\text { total benefits }\end{array}$ & 539 & 21 \\
\hline Spain $^{14}$ & 4.7 & 23.6 & None & 912 & 53 \\
\hline $\begin{array}{l}\text { United } \\
\text { Kingdom }^{14}\end{array}$ & $6-10$ & 12.2 & $\begin{array}{l}\text { Means testing } \\
\text { and up to } 17 \% \\
\text { of total benefits }\end{array}$ & 711 & 73 \\
\hline $\begin{array}{l}\text { United } \\
\text { States }\end{array}$ & 6.2 & 6.2 & None & 976 & 28 \\
\hline
\end{tabular}

contributions from the private sector or government (Table 3).

- Disability is defined broadly in terms of a substantial inability to maintain gainful employment (Table 4). Many countries define more than one category of disability based on the percentage of work capacity that is limited and linked to benefit levels. However, we focus only on those qualifying for $100 \%$ LTD compensation.

\section{Disability Criteria}

The procedure by which a worker seeking disability is declared eligible is similar across countries. ${ }^{21-23}$ The procedure typically begins with an individual's making an application to the responsible agency. A medical exam is performed to determine the level of physical impairment. Following the medical assessment, an administrative review is conducted that generally considers type of employment, work history, medical records, and recent medical examinations. Interviews with the person seeking disability coverage are often conducted prior to final disability eligibility determination.

The determination of disability is based on multiple criteria; medical assessments of physical impairment are just one component of that judgment. Most countries do not have specific physiological criteria established for the large number of conditions that may lead to disability. Rather, they rely on overall assessments of the impact a medical condition has on a person's ability to perform productive work. Only Japan and the United States have respiratory-specific criteria for establishing eligibility for respiratory-related disability (Table 4).

The Japanese respiratory criteria are subjective categorizations of restrictions to activities in home and social environments. Such measures appear to be related to quality-of-life measures such as the physical and social functioning indices of the ShortForm 36 Health Survey. In addition, while criteria are defined as respiratory-specific, they are relevant to virtually any disease state.

The SSA's "Blue Book" provides explicit spirometric criteria to evaluate respiratory-related impairment. ${ }^{18}$ These criteria are minimum $\mathrm{FEV}_{1}$ thresholds for given height ranges. The criteria do not account for normal variations in gender, age, or race or nonlinearities with height, as would be possible when using established spirometric reference values.

\section{Estimated Impact of COPD on LTD Programs}

We found no studies in the international English-language literature to adequately quantify the impact of COPD on LTD programs. Accurate epidemiological data that could be used to quantify such impact has been described as difficult and expensive to collect for several reasons. ${ }^{7.24}$ First, determination of disability due to COPD is not objectively codified in most countries. This makes extracting data difficult. Second, COPD is usually only diagnosed in its end stages; therefore, its role in disability compensation prediagnosis cannot be correctly assessed. Third, COPD has been recognized as not just one disease but as a group of diseases with multiple differential diagnoses; therefore, diagnosis is variable and imprecise, and morbidity and ensuing disability are difficult to quantify. Finally, it is a disease more likely to be cited as a contributory rather than an underlying cause of mortality. In many instances, it is not quoted at all. Thus, we applied a deterministic model (described under "Methods") for estimating a range of the potential burden of COPD on LTD.

By applying the SSA respiratory-specific disability eligibility criteria to the U.S.-based NHANES data, we estimated that 0.54\% of the working-age population are potentially eligible for respiratory-related disability. Table 5 lists the derived minimum and maximum estimates of working-age persons in each study country who would be eligible for respiratory-related LTD.

Figure 1 illustrates our estimates for the potential financial impact of COPD on government-administered LTD programs. The maximum potential burden of COPD, corresponding to the maximum number of persons eligible for disability, and the minimum estimated burden, corresponding to the minimum number of eligible persons, are depicted. Bars representing variation due to differences in COPD prevalence are also shown. In summing up the results of Figure 1, it can be said that the total estimated burden of COPD-attributable disability in the 
8 countries studied is substantial. If disability enrollment rates are comparable to those in the United States in 2000, the total burden in all study countries is estimated at $\$ 5$ billion annually. The burden could be as high as $\$ 25$ billion annually if all persons estimated to meet U.S. eligibility criteria are granted disability compensation.

As shown in Figure 2, on a per capita basis, France is estimated to bear the greatest financial burden of about $\$ 14.30$ to $\$ 74$ per person of working age per year. This is due largely to the generous benefits paid by the French disability program—about $44 \%$ of the average private sector wage. Coupled with relatively high wage rates, France leads in this category. Germany $(\$ 12.80$ to $\$ 66.50$ ), the United States (\$12.20 to $\$ 63.20$ ), and Spain (\$11.40 to $\$ 59.10$ ) also have high estimated per capita costs. Despite low benefit levels of $26 \%$ of private sector wages, the United States has high private sector wages, thus balancing the relatively low benefit levels.

\section{Discussion}

Public policy decisions regarding allocation of scarce health care resources are increasingly reliant on the results of economic analyses. Thus, the definition of potential financial impact of COPD on LTD pensions in these 8 countries is a major concern. Our estimates suggest that the total burden in these countries could range from $\$ 5$ billion to as high as $\$ 25$ billion per year if all persons potentially eligible for respiratory-related disability were granted compensation. Thus, COPD-related disability could result in significant expenditures for payers.

Spirometric criteria for disability, used by SSA guidelines, have the advantage of being based on objective measurements obtained by simple spirometry. However, pulmonary function testing (PFT) has since been criticized as a measure of disability due to the limited correlation between PFT and actual physical impairment. ${ }^{25}$ In fact, our results show a 5-fold difference between the "potential" number of eligible persons using the SSA criteria and the "actual" number of eligible persons from SSA records; this difference suggests that spirometric criteria may not be particularly useful in making the disability determination.

More recently, cardiopulmonary exercise testing (CPET) has been called the "gold standard" for assessing impairment primarily because of the limitations of spirometry testing. ${ }^{8}$ The rationale behind this is that if the physical demands of work are put in terms of oxygen consumption, CPET is a better proxy for oxygen consumption than is PFT. ${ }^{26}$ The main drawbacks to cardiopulmonary exercise testing are that (1) it is not commonly available, (2) it is not easily performed, and (3) it is relatively costly.

There is as yet no explicit consideration of respiratory symptoms in disability determinations. However, European guidelines for medical assessments of physical impairment touch on symptoms as they correspond to an inability to work. ${ }^{27}$ In addition, some recent research indicates stronger links

\begin{tabular}{|c|c|}
\hline Country & Definitions of Respiratory Disability \\
\hline Canada & $\begin{array}{l}\text { Eligibility is not based on a list of any specific disabilities, } \\
\text { disease states, or body system impairments. Rather, } \\
\text { eligibility is based on conformity to Canada Pension Plan's } \\
\text { definitions. }{ }^{38}\end{array}$ \\
\hline France & $\begin{array}{l}\text { An assessment of disability is not based on the physical } \\
\text { incapacity itself, but, rather, it is based on the impact of } \\
\text { the physical incapacity on the worker's earnings. The } \\
\text { assessment of disability is based on a review of the gravity } \\
\text { and nature of physical incapacity in conjunction with the } \\
\text { age of the worker, physical/ mental capacity, vocational } \\
\text { training, etc. }{ }^{14}\end{array}$ \\
\hline Germany & $\begin{array}{l}\text { The question of whether an illness exists within the meaning } \\
\text { of labor law has to be judged from the circumstances in } \\
\text { each particular case, especially the nature and severity of } \\
\text { the condition and the type of work performance due. }{ }^{14}\end{array}$ \\
\hline Italy & None specific ${ }^{14}$ \\
\hline Japan & $\begin{array}{l}\text { Level of disability pension payment is based on grade of } \\
\text { disability. } \\
\text { Grades of impairment of respiratory organs: } \\
\text { - Grade 1: Daily activity in the home is significantly limited } \\
\text { - Grade 2: Daily social activity is significantly limited }\end{array}$ \\
\hline Spain & None specific ${ }^{14}$ \\
\hline United Kingdom & Disability is based in part on a medical assessment ${ }^{14}$ \\
\hline United States & $\begin{array}{l}\text { Chronic obstructive pulmonary disease due to any cause, } \\
\text { with FEV } 1 \text { equal to or less than the values specified in } \\
\text { Table } 1 .{ }^{18}\end{array}$ \\
\hline
\end{tabular}

between respiratory symptoms and measures of impairment.

More cost-effective indicators of disability have been suggested but are not widely accepted. Bestall et al. ${ }^{28}$ conclude that the Medical Research Council dyspnea scale may be a simple and inexpensive method for evaluating physical impairment. The strong correlations between Medical Research Council scores and quality-of-life indices suggest that the St. George Respiratory Questionnaire (SGRQ) and the Nottingham Extended Activities of Daily Living (EADL) scale may also be cost-effective indicators of physical impairment. These findings are especially relevant in light of the fact that the ability to work is not dependent on oxygen consumption alone. Symptoms such as chronic cough, sputum production, and dyspnea that interfere with communications or cause respiratory-related drowsiness may render workers effectively disabled. ${ }^{29}$

There is also evidence that recognition of respiratory-related disabilities may be on the rise among those affected. Combined with the effects of antidiscrimination legislation and patients' rights movements, the financial impact of COPD-related disability on health care utilization may also become a concern. For example, the Rehabilitation Act of 1973 and the Americans with Disabilities Act of 1990 have been in place in the United 


\section{FIGURE 1 Potential Total Burden of COPD-Related Disability (U.S. [2000] Dollars)}

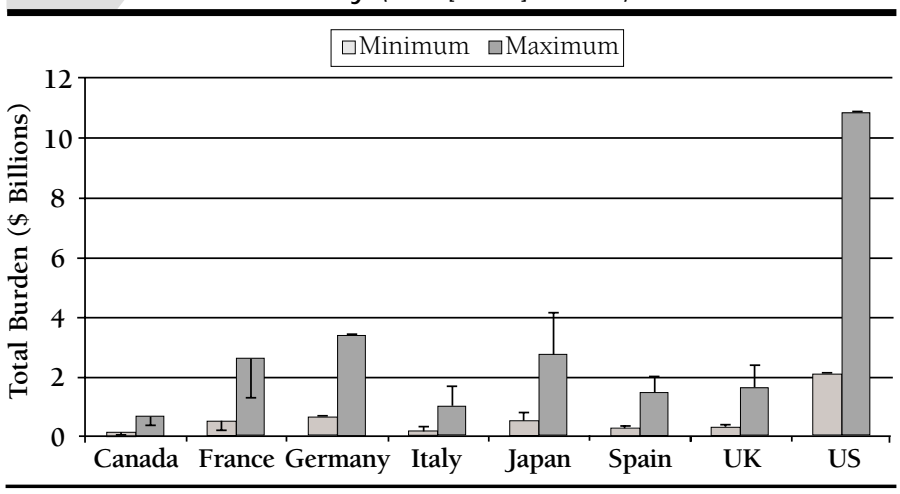

Note: Minimum and maximum estimates are based on compensation rates (Table 3) and estimated number of working age eligible for long-term disablity (Table 5). Whisker bars represent estimated burden based on variations in country-specific estimates of COPD prevalence (Table 2), which are used as proxies for variation in prevalence of respiratory-related disability. $\mathrm{COPD}=$ chronic obstructive pulmonary disease.

\section{(FIGURE 2 Potential Burden of COPD-Related Disability per Person of Working Age (U.S. [2000] Dollars)}

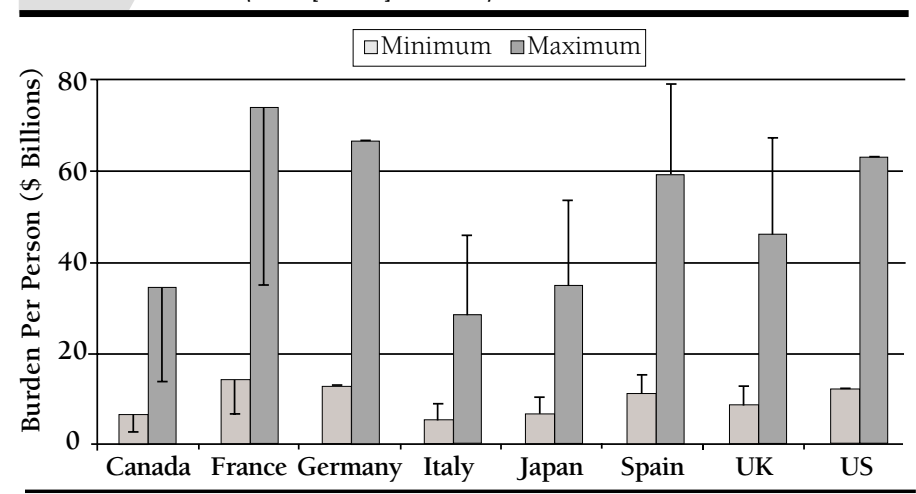

Note: Minimum and maximum estimates are based on compensation rates (Table 3) and estimated number of working age eligible for long-term disability (Table 5). Whisker bars represent estimated burden based on variations in country-specific estimates of COPD prevalence (Table 2), which are used as proxies for variation in prevalence of respiratory-related disability.

$\mathrm{COPD}=$ chronic obstructive pulmonary disease.

States for some time. Nonetheless, the extent to which they may increase health care utilization among those with physical disabilities is still uncertain, as they have been little tested in the courts. Moreover, while these statutes may tend to increase health care utilization by guaranteeing access to care, at the same time, they tend to decrease pension burdens by emphasizing rights to employment.
The present analysis is necessarily based on limited respiratory-specific eligibility criteria data. GOLD guidelines define spirometry as essential to diagnosis of COPD. ${ }^{8}$ They categorize spirometry results for assessment of severity and monitoring of COPD but do not attempt to categorize symptoms (except respiratory failure). These guidelines have been designed only as a very general approach to management, but their deficiency makes it evident that measures need to be developed and evaluated for COPD disability evaluation. In contrast, National Institute for Clinical Excellence guidelines assert there is no single diagnostic test for COPD. ${ }^{30}$ They describe spirometry as a poor predictor of disability and quality-of-life assessment in COPD sufferers and recommend that clinical judgment rather than pulmonary function test results should form the basis of management.

Most notably, our current understanding of the national-level financial impact of COPD on LTD could be improved by development of clear eligibility criteria to facilitate data collection. A codification of symptoms combined with physical status could achieve this. Strong correlations between Medical Research Council scores and the quality-of-life indices suggest that SGRQ or EADL may be combined with spirometry to create a cost-effective indicator of disability in COPD.

We structured our estimates to include only the national LTD programs. This method made 2 things possible: (1) consistency of program aims and covered populations across all study countries and (2) availability of readily accessible English-language sources. We did not attempt to describe the entire universe of disability programs that may cover COPD-related disability. Other programs may also provide funds for disability due to COPD. In the United States, for example, there are private sources (including various LTD policies supported by employer contributions and individually purchased plans) and other public programs for specific populations such as the United Mine Workers Fund. A similar constellation of public and private programs provides funds that may supplement national LTD programs. However, gathering consistent information across all programs and countries was beyond our aims for this assessment.

\section{Conclusion}

The potential burden of COPD on LTD is quite large, but the lack of available data results in substantial uncertainty internationally about what the actual burden is. In the face of limited information, U.S. managed care organizations may have difficulty estimating future pharmacoeconomic and total economic costs of care for this patient population. Internationally, the lack of standard criteria to identify patients with respiratory-related disability may lead to under-recognition of COPD's true impact by hampering the ability to estimate the current impact and project the burden into the future. In addition, cross-country comparisons are severely limited. Further work is needed to develop consistent and more cost-effective ways to measure the impact of COPD and to ensure equitable access to compensation 
TABLE 5 Estimated Numbers of Persons Eligible for SSA-Determined Respiratory-Related Disability

\begin{tabular}{l|c|c|c|c|c|c|c|c}
\hline & Canada & France & Germany & Italy & Japan & Spain & United Kingdom & United States \\
\hline Minimum & 20,527 & 36,677 & 53,140 & 37,615 & 81,690 & 26,049 & 37,094 & 178,279 \\
\hline Maximum & 106,380 & 190,080 & 275,400 & 194,940 & 423,360 & 135,000 & 192,240 & 923,940 \\
\hline
\end{tabular}

Note: Estimated numbers are calculated as: Maximum = proportion eligible using U.S. Social Security Administration (SSA) criteria (0.54\%) X number of working-age population; Minimum =U.S. maximum/ratio of maximum to actual number receiving SSA long-term disability benefits (=5.18).

for COPD patients. Establishing the link between symptoms and worker disability may hold promise. The wide disparity we observed between the number of persons in the United States who meet SSA spirometric criteria for disability and the number (one fifth) who actually obtain disability compensation confirms the idea that pulmonary function tests, while objective, alone may not be an appropriate criterion for assessment of disability. We propose that CPET and the SGRQ or EADL questionnaires be combined with spirometry to create more useful respiratory-specific disability criteria.

\section{DISCLOSURES}

Funding for this research was provided by a grant from Boehringer Ingelheim Pharmaceuticals, Inc., and was obtained by author Sharon Isonaka. Isonaka and authors Robert J. Nordyke and Dorothy George are employed by Cerner Health Insights (formerly Zynx Health), which consults with Boehringer Ingelheim; author Keith DesFosses is employed by Constella Health Strategies, which consults with Boehringer Ingelheim; at the time of this study, author Dmitry Nonikov was employed by Boehringer Ingelheim; author David Tinkelman discloses no potential bias or conflict of interest relating to this article.

Part of the material in this article was presented as a poster at the 13th Annual Congress of the European Respiratory Society in Vienna in September 2003. The sponsor organization assisted in the critical review of this manuscript. Tinkelman served as principal author of the study. Study concept and design were contributed by Tinkelman, Nordyke, and Isonaka. Analysis and interpretation of data were contributed by all authors; statistical expertise was contributed by Nordyke. Drafting of the manuscript was the work of Nordyke, Isonaka, and DesFosses, and its critical revision was the work of all authors.

\section{REFERENCES}

1. National Institutes of Health: National Heart, Lung, and Blood Institute. Chronic Obstructive Pulmonary Disease. Bethesda, MD: National Institutes of Health: National Heart, Lung, and Blood Institute; March 2003. NIH Publication 03-5229.

2. Halbert RJ, Isonaka S, George D, Iqbal A. Interpreting COPD prevalence estimates: what is the true burden of disease? Chest. 2003;123:1684-92.

3. Murray CJL, Lopez AD. The Global Burden of Disease: A Comprehensive Assessment of Mortality and Disability from Disease, Injuries and Risk Factors in 1990 and Projected to 2020. Cambridge, MA: Harvard University Press; 1996.

4. Rudkin ST, Smith, RP, White RJ. The impact on careers of disability due to chronic obstructive pulmonary disease (COPD). Thorax. 1996;51(suppl 3): A16. Abstract S63.

5. Sexton DL, Munro BH. Impact of a husband's chronic illness (COPD) on the spouse's life. Res Nurs Health. 1985;8:83-90.

6. Shepperd S, Harwood D, Jenkinson C, Gray A, Vessey M, Morgan P. Randomised controlled trial comparing hospital at home care with inpatient hospital care. I: three month follow up of health outcomes. BMJ. 1998;316 (7147):1786-91.
7. Mannino DM, Ford ES, Redd SC. Obstructive and restrictive lung disease and functional limitation: data from the Third National Health and Nutrition Examination. J Intern Med. 2003;254:540-47.

8. National Institutes of Health: National Heart, Lung, and Blood Institute. Global Strategy for the Diagnosis, Management, and Prevention of Chronic Obstructive Pulmonary Disease. Bethesda, MD: Global Initiative for Chronic Obstructive Lung Disease, World Health Organization, National Heart, Lung, and Blood Institute; 2003. Available at: www.guideline.gov. Accessed January 4, 2005.

9. den Otter JJ, van Dijk B, van Schayck CP, Molema J, van Weel C. How to avoid underdiagnosed asthma/chronic obstructive pulmonary disease? J Asthma. 1998;35:381-87.

10. Wouters EF. Economic analysis of the Confronting COPD survey: an overview of results. Respir Med. 2003;97(suppl C):S3-S14.

11. Eisner MD, Yelin EH, Trupin L, Blanc PD. The influence of chronic respiratory conditions on health status and work disability. Am J Public Health. 2002;92:1506-13.

12. Druss BG, Marcus SC, Olfson M, Pincus HA. The most expensive medical conditions in America. Health Aff (Millwood). 2002;21:105-11.

13. Okuno E. Disability Statistics in Japan. Disability Information Resources. Available at: www.dinf.ne.jp/doc/english/asia/resource/z00ap/003/z00ap00309.htm. Accessed November 15, 2002.

14. Mutual Information System on Social Protection (MISSOC) in the EU Member States and the EEA. Invalidity Data. 2002. Available at: europa.eu.int/comm/employment_social/missoc/index_en.html. Accessed November 15, 2002.

15. Mannino DM, Homa DM, Akinbami LJ, Ford ES, Redd SC. Chronic obstructive pulmonary disease surveillance-United States, 1971-2000. MMWR Surveill Summ. 2002;51:1-16.

16. Petty TL. Definitions, causes, course, and prognosis of chronic obstructive pulmonary disease. Respir Care Clin N Am. 1998;4:345-58, vii. 17. Ringbaek T, Viskum K. Has the perception of disability among COPD patients applying for pension changed during the last 20 years? Respir Med. 2001;95:398-403.

18. U.S. Social Security Administration. Disability Evaluation Under Social Security. (Also known as the "Blue Book.") Baltimore, MD: U.S. Social Security Administration, Office of Disability Programs; January 2003. Report 64-039.

19. National Center for Health Statistics. The Third National Health and Nutrition Examination Survey (NHANES III, 1988-94) Reference Manuals and Reports. 96. Available at: www.cdc.gov/nchs/about/major/nhanes/ datalink.htm\#NHANESIII. Accessed November 15, 2002.

20. U.S. Social Security Administration. Annual Statistical Supplement, 2001. Baltimore, MD: U.S. Social Security Administration, Office of Research, Evaluation, and Statistics; 2001

21. Canada Pension Plan (R.S. 1985, c. C-8 ). Department of Justice, Canada. Available at: laws.justice.gc.ca/en/C-8/. Accessed November 15, 2002.

22. Japan: A Web Guide. Society, Social Security. Foreign Press Center, Japan. Available at: www.fpcj.jp. Accessed November 15, 2002.

23. U.S. Social Security Administration. Annual Report of the Supplemental Security Income Program, 2004. Baltimore, MD: U.S. Social Security Administration; 2004. 
24. Briggs DD, Jr. Chronic obstructive pulmonary disease overview: prevalence, pathogenesis, and treatment. J Manag Care Pharm. 2004;10(4)(suppl S-a):S3-S10.

25. Oren A, Sue DY, Hansen JE, Torrance DJ, Wasserman K. The role of exercise testing in impairment evaluation. Am Rev Respir Dis. 1987;135:230-35.

26. Harber P, Fedoruk MJ. Work placement and worker fitness. Implications of the Americans with Disabilities Act for pulmonary medicine. Chest. 1994;105:1564-71.

27. Cotes JE. Rating respiratory disability: a report on behalf of a working group of the European Society for Clinical Respiratory Physiology. Eur Respir J. 1990;3:1074-77.

28. Bestall JC, Paul EA, Garrod R, et al. Usefulness of the Medical Research Council (MRC) dyspnoea scale as a measure of disability in patients with chronic obstructive pulmonary disease. Thorax. 1999;54:581-86.

29. Mehlman MJ, Durchslag MR, Neuhauser D. When do health care decisions discriminate against persons with disabilities? J Health Polit Policy Law. 1997;22:1385-411.

30. National Collaborating Centre for Chronic Conditions. Chronic obstructive pulmonary disease: management of adults with chronic obstructive pulmonary disease in primary and secondary care. Thorax. 2004;59(suppl 1): $1-232$.

31. Chen Y, Breithaupt K, Muhajarine N. Occurrence of chronic obstructive pulmonary disease among Canadians and sex-related risk factors. J Clin Epidemiol. 2000;53:755-61.
32. Rennard S, Decramer M, Calverley, PM, et al. Impact of COPD in North America and Europe in 2000: subjects' perspective of Confronting COPD International Survey. Eur Respir J. 2002;20:799-805.

33. Viegi G, Pedreschi M, Pistelli F, et al. Prevalence of airways obstruction in a general population: European Respiratory Society vs. American Thoracic Society definition. Chest. 2000;117:339S-345S.

34. Fukuchi Y, Nishimura M, Ichinose M, et al. Chronic obstructive pulmonary disease (COPD) in Japan: the Nippon COPD epidemiology (NICE) study. Respirology. In press.

35. Pena VS, Miravitlles M, Gabriel R, et al. Geographic variations in prevalence and underdiagnosis of COPD: results of the IBERPOC multicentre epidemiological study. Chest. 2000;118:981-89.

36. Dickinson JA, Meaker M, Searle M, Ratcliffe G. Screening older patients for obstructive airways disease in a semi-rural practice. Thorax. 1999;54:501-05.

37. Mannino DM, Gagnon RC, Petty TL, Lydick E. Obstructive lung disease and low lung function in adults in the United States: data from the National Health and Nutrition Examination Survey, 1988-1994. Arch Intern Med. 2000;160:1683-89.

38. E-mail communication between Keith DesFosses and Human Resources Development Canada, Old Age Security and Canada Pension Plan Office; November 11, 2002. 